disruptive discharge would take place in air, and could only be obtained in vacuo. In a footnote, however, Becquerel tells us that he has since observed the electric deviation in air with a field of about $10^{12}$ C.G.S. units, and has found for certain rays which pass through black paper the values $m / e=10^{7}$ and $v=1 \cdot 6 \times 10^{10}$.

The chemical effects of Becquerel rays have been examined by M. and Mme. Curie and Becquerel; they may be briefly summarised here. The rays from active salts of barium transform oxygen into ozone, a process involving a continuous expenditure of energy. Potassium iodide is coloured blue. Glass in contact with the salts is coloured violet, ultimately becoming nearly black, and the colour penetrates the glass; this phenomenon is analogous to the coloration of fluorspar by kathodic rays. Platinocyanide of barium screens gradually turn yellow, then brown, and finally lose their fluorescence, which, however, is restored by exposure to sunlight. Fluorine continues to phosphoresce for twenty-four hours after being excited, and calcined fluorspar which has lost its phosphorescence regains its luminosity in the presence of radium. Chemical activity is confined to those radioactive preparations which are luminous, but is not always proportional to the luminosity.

According to the Curies' experiments, powerfully radioactive compounds of radium and polonium, when they act on inactive substances, are able to communicate radioactivity to them. This induced radio-activity increases with the time of exposure up to a certain limit. If the inducing substance is 5000 to 50,000 times the activity of uranium, the induced activity may amount to fifty times that of uranium. It is reduced to one-tenth of its amount in an hour after removal, but it may persist for many days, finally disappearing. The emanation of radio-active particles from thorium compounds, investigated by Rutherford, is remarkable. This emanation ionises the gas in its neighbourhood, and it will pass through thin layers of metal, through thicknesses of paper, or through a plug of cotton wool. It is also unaffected by bubbling through hot or cold water, weak or strong sulphuric acid. The emanation retains its radio-active power for some minutes, gradually losing it. The positive ion produced in the gas by the emanation was found to possess the power of inducing radio-activity in all substances on which it fell, this power of giving radiation lasting several days. Whether the emanation be a vapour of thorium is doubtful.

The question as to the amount of energy emitted by the Becquerel rays has already been referred to in NATURE, and need not therefore occupy our space further now. The problem of discovering the seat of this energy would seem of late to have taken another form. At first it was supposed that a difficulty would exist in reconciling the continuous emission of these rays with the principle of conservation of energy; now, however, that the amount of the emitted energy has been estimated, the difficulty is seen to lie in the experimental observation of changes of such inappreciable magnitude as would suffice to generate this energy.

Before 1896 physicists were just beginning to grasp Maxwell's theories, and to realise more clearly the simplification introduced into notions electric and optical by the conception of the ether. The discovery of rays capable of discharging electrified bodies in air has not only shown the fallacy of our preconceived dogmatic notions as to the division of substances into conductors and dielectrics, but has taught us that the properties of the ether are not so simple as we had anticipated. We can only wonder whether Maxwell would have been able to develop his electromagnetic and electro-optic theories had the complications arising from Becquerel and other rays been before him, and the want now makes itself felt of a second Maxwell, who shall co-ordinate the newlyaccumulated mass of experimental facts into the form of a connected mathematical theory.

G. H. BRYAN.

\section{MODERN MICROSCOPES.}

$\mathrm{I}$ spite of the attention which has of late years been paid to the improvements of every detail of microscope construction, it is remarkable how Powell's No. I stand has now existed, practically unchanged, for some fifty years. It may therefore be considered a permanent type, and it is one to which the best modern instruments conform more and more. Its most obvious peculiarity, however, a tripod base, has not yet become general. The heavy horseshoe foot is still in all but universal favour on the Continent, although Powell's base is occasionally imitated. Thus the Leitz firm in 1893 , and the Hartnack firm in 1898 , brought out large model microscopes on a tripod base ; Greenough's low-power stereoscopic binocular microscope (I898) is similarly equipped. This last instrument, which is the most recent binocular novelty, is highly esteemed. It is made by Zeiss, is fitted with porro prisms, and, among other advantages, affords views of the under as well as the upper side of an object.

English makers have lately paid much attention to the perfecting of cheaper stands with some excellent results. In their new model and educational microscope, Messrs. Ross have reintroduced the principle of a reversing and locking foot, which was first invented by Cuff (circa I765). By this means the instrument acquires great stability when used horizontally. The same firm, in their bac. teriological microscope, use a tripod stand, of which the hind toe is made to fold forward between the two fixed front toes when not in use, thereby economising space in packing. The stage of this, as well as of Baker's microscopes, is fitted with the Nelson horseshoe perforation. The advantage of this device is that in highpower work, when the objective necessarily works very close to the cover glass, the slide can be tilted with the finger, and the focus gradually attained with far less risk to the object than if the slide rested immovably on the stage.

Messrs. R. and J. Beck's student's microscope and Messrs. W. Watson's "Fram" microscope are other examples of really good, small, cheap microscopes. Economy is obtained, not by sacrificing quality of work, but by simplifying the design. Every step in the direction of reducing the cost of a good instrument is too obviously desirable to require demonstration. Some designs strive after cheapness by using a fine adjustment, and trusting to a push-tube motion for the coarse. But if a microscope is to have only one adjustment, most microscopists will prefer a good coarse to an indifferent fine adjustment. This is the principle of Messrs. Watson's school microscope, which has a coarse adjustment only (diagonal rack and pinion), so good that a $\frac{1}{8}$-inch objective can be accurately focussed with ease. The cost, with eye-piece and objectives, is only three pounds.

The practical difficulty is, of course, that the great amount of wear upon the coarse adjustment affects in time the evenness of the racking, and produces loose action. But an important piece of progress towards obviating this trouble has been made by Mr. E. M. Nelson, who has applied the principle of stepped rackwork (Fig. I). The two similar racks are placed so that their teeth are slightly out of step, the amount of divergence being regulated by the upper right-hand screw. The two screws in the centre of the pinion regulate the pressure by which the pinion is forced into the rack. The advantage of the arrangement is not only compensation for wear and tear, but rapidity and smoothness of action, for the tube obeys the slightest movement of the milled heads. If experience confirms the favourable opinion with which this novelty has been received, the necessity of a fine adjustment in cheaper stands will disappear.

I Fuller accounts of all the in itruments referred to will $b$ efound in the Journal of the Ruyal Microscopical Society for $1897,1898,1899$ and 1900. 
Another coarse adjustment improvement has been made by Herr Reichert. Its principle is a rack and pinion of specially hardened gun-metal, and a very important feature is the springing with adjusting screws for tightening up. Of these there are three: one being used for regulating the grip on the tube-mount, the others for tightening the pinion; thus the unavoidable wear and tear can be compensated for.

Fine adjustments, owing to the rigorous requirements of high-power photomicrography, have received very great attention. ${ }^{1}$ Modern advances may, however, be reduced to some five main types: (I) the direct-acting

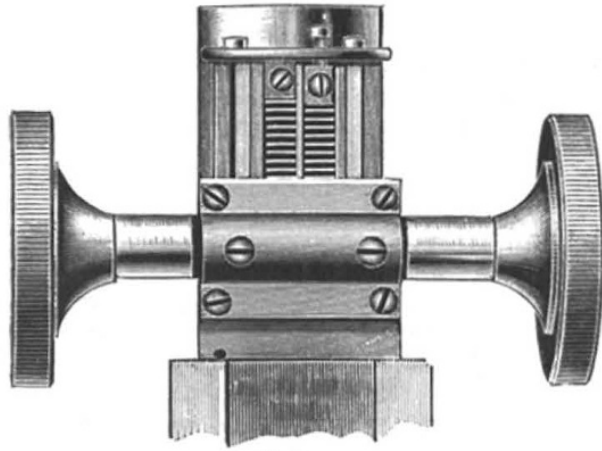

FIG. I.

screw, (2) the same with lever interposed, (3) the differential screw, (4) Reichert's lever fine acting, (5) Berger's endless screw. The first of these is seen in the Zeiss' microscope (1886), where a left-handed micrometer screw with a hardened steel point presses on a hardened steel plate. In this, one revolution of the milled head causes a movement of $1 /$ ror inch. The second is met with in Messrs. Watson's microscope, where a lever of the first kind with unequal arms is interposed. This arrangement not only greatly reduces the weight bearing on the fine adjustment, but slows the speed down to $1 / 350$ inch for one revolution. This speed is not at all too slow, as any lens possessing a fair optical index is excessively
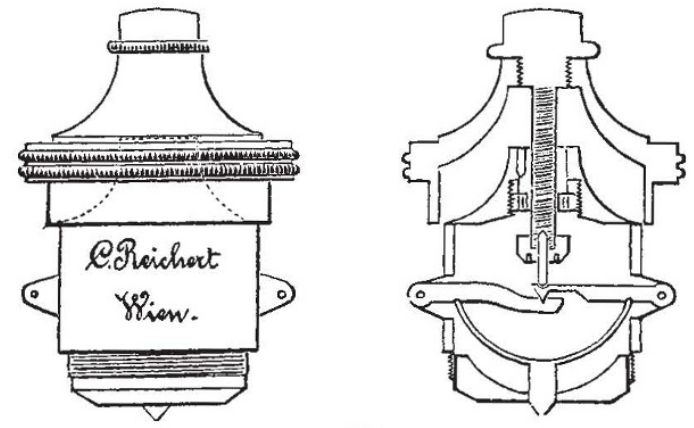

FIG. 2 .

sensitive to focal adjustment when a $\frac{3}{4}$ illuminating cone is used. The differential screw fine adjustment occurs in the microscopes of Messrs. Baker and Messrs. Swift. Its advantage is that fine movements are obtained by the use of coarsely threaded screws, thus reducing the liability to wear and tear. Any degree of slowness may be obtained, but $1 / 200$ inch is adopted by the makers. Herr Reichert's fine adjustment is especially suited to the Continental model, and consists of an ingenious adaptation of a double lever of the second order to the usual direct-acting screw (Fig. 2). It is arranged for a movement of $\mathrm{I} / 200 \mathrm{inch}$.

1 For fuller information see "On the Evolution of the Fine Adjustment," by Mr. E. M. Nelson (Journal R.M.S. I899, pp. 366-375).

$$
\text { NO } 1593 \text {, voL. 62] }
$$

Herr Berger's (Zeiss) is another great improvement in fine adjustments, and is on an entirely novel plan. The extremity of the micrometer screw comprises a horizontal toothed-wheel, which is actuated by an endless screw, terminating in the usual micrometer knobs. This arrangement permits of any degree of sensitiveness, and is ingeniously packed away in a hollow part of the limb, so that the fine adjustment is both dustproof and out of risk from any accidental injury. A valuable feature in the contrivance is a device for preventing strain on the fine adjustment from over-winding. This particular microscope is intended for the highest class of work, and possesses another good feature, in that the arm can be made to extend to any length over the stage without increasing the pressure on the fine adjustment. Thus an error in the original design of the Continental model, viz. the shortness of the distance between the limb and the optic axis, is corrected.

In Pillischer's international microscope a serious attempt has been made to reduce the inconveniences inseparable from stage-clips. He secures these to a bar, which, by means of a flange piece, raises or lowers them simultaneously, so that their points press on the object slide with any desired degree of pressure.

The use of large slides has led to a corresponding increase in the size of the stage, as well as in improved stage-finders and mechanical movements. There is a marked tendency to make the stages completely rotatory.

Among special stages, that of Herr Kraus (Reichert and Co.) is perhaps the most notable. It is heated by an electric current passed through a coil of platinum immersed in the liquid paraffin with which the stage box. is filled. Regulation is accomplished by an ingenious contact thermometer, a device which resembles an ordinary thermometer, except that it is open at the top. end. A platinum thread can be set in the tube at any desired temperature, and, when the mercury has risen and has met this thread, an automatic arrangement switches off the supply current. If the platinum and the mercury break contact, the current re-enters. The apparatus is said to be capable of rapidly producing and sustaining a temperature constant to $\mathrm{O}^{\circ}{ }^{\circ} \mathrm{C}$.

In the department of lenses, Messrs. Watson havebrought out their holoscopic eye-pieces, in which one lens-mount slides within the other, telescope fashion, thus forming a very convenient arrangement, easily adjustable as an over-corrected or under-corrected ocular as desired. The appropriate graduations are engraved on the tube.

Messrs. Zeiss have issued, at Dr. Hartwig's suggestion, a very useful series of low-power objectives, called "planktonsearchers," which are to be immersed in a trough of water, and so used for exploring it. They are made of Jena glass, and present an image completely plane and free from astigmatism quite close up to the periphery. The microplanar series of objectives by the same firm are used for projecting micro-slides on a screen, and give a wonderfully good ten-feet picture remarkably plane, sharp and well-defined, even to the limits of the field.

Another important set of objectives is Messrs. Leitz' series of achromatics. These are made of Jena glass free from fluorite. They are so well designed and corrected that they give results but very little inferior to the best apochromatics. Their freedom from fluorite renders the risk of atmospheric deterioration insignificant. Moreover, they are sold at so low a price that Messrs. Leitz must be admitted to have outstripped all other opticians in this particular detail.

Mr. H. J. Grayson, of Melbourne, has by an unknown process produced some very fine examples of ruled testplates, the rulings being executed in various gradations of fineness, as far as 60,000 lines per inch, and 2000 lines per millimetre. The accuracy of the work is remarkable 
and the mounting in realgar $(\mu=2.5)$ makes the lines stand out with a distinctness and brilliancy hitherto unknown.

The Royal Microscopical Society have, after careful consideration and after full consultation with microscope makers, drawn up a code of standard sizes for eye-pieces and sub-stage fittings. It is to be hoped that this important and useful step towards universality will be generally adopted.

Alfred N. Disney.

\section{THE FORTHCOMING MEETING OF THE} BRITISH ASSOCIATION.

THE meeting of the British Association, which is to be held in Bradford this year, promises to be an unusually large and important one. Bradford being midway between London and Edinburgh, serves as a common meeting-ground for scientific men from the south of England and from Scotland and Ireland, and it is within easy reach of the Midland and Northern University Colleges. Bradford and Leeds are so close together that for such a purpose as this they are almost one city, and the Bradford Committee, therefore, have the advantage of the Yorkshire College being practically on the spot. The last meeting of the British Association in Bradford was held in 1873 , but since that time the city (which, by the way, was then only a town) has practically been re-built, and has grown and developed in a manner resembling the progress of an American rather than that of an English town.

It is, therefore, much better provided now with hotel accommodation and with public buildings suitable for reception and sectional rooms. It is probable that the number of visitors will be far above the average ; already some sixty or seventy Fellows of the Royal Society have announced their intention of being present, and professors and eminent lecturers from nearly every University in England, Scotland and Ireland have promised to attend. The Church will be represented by the Bishop of Ripon, the legal profession by the Master of the Rolls and Lord McLaren, and the names of over a score of members of both Houses of Parliament have been sent in.

The meeting will commence on Wednesday, September 5, when the new President, Prof. Sir Wm. Turner, of Edinburgh, will deliver his address in St. George's Hall. On the following evening the Mayor of Bradford will give a conversazione in St. George's Hall, at which it is hoped there will be exhibits illustrating the most recent scientific work. On Friday evening the lecture will be delivered in St. George's Hall by Prof. Gotch, F.R.S., on "Animal Electricity." The lecture to artisans on the Saturday will be given by Prof. Silvanus Thompson, F.R.S., and it is expected that there will be an audience in St. George's Hall of 4000 to 5000 working men. On Monday afternoon the Mayor and Corporation will give a garden-party in Lister Park, and in the evening an address will be given by Prof. W. Stroud on "Range-Finders." The Mayor and Corporation will give another large conversazione on Tuesday evening, and on the Wednesday evening a concert will take place in St. George's Hall with the Permanent Orchestra and the Festival Choral Society, under the conductorship of Mr. Fredk. Cowan. There will also be one or two eminent vocalists.

During the week there will be a textile exhibition at the Technical College, which will illustrate the various processes of the local industries, and the machinery employed can be seen in motion. There will be a reception at the College on Thursday afternoon, September 6, and the smoking concert in honour of the President will also be given at the Technical College, after Prof. Gotch's lecture on Friday.

$$
\text { NO. I } 598 \text {, VOL. } 627
$$

Excursions to places of interest in the neighbourhood will be made on Saturday, the 8th, and on Thursday, the I $3_{\text {th }}$; among the places selected are Bolton Priory, Ripon and Fountains Abbey, Malham, Clapham and Ingleton, the Nidd. Valley, Farnley Hall, Haworth, Ilkley, Knaresboro' and Harrogate.

It has become an established custom to publish locally in the towns visited by the British Association a handbook containing a review of the objects of scientific interest and of the social and industrial conditions which prevail in the district. Many of these handbooks have been excellent in their character, and have covered ground altogether unexplored by the ordinary guidebook.

There is every prospect that the handbook published in connection with the Bradford meeting of the Association will be marked by the same width of view and thoroughness of execution, and may prove of permanent value. The work has been taken up with energy by the Publications Committee, of which Mr. Harry Behrens is chairman, and $\mathrm{Mr}$. Mortimer Wheeler is honorary secretary and editor.

The book will be divided mainly into three sections. The earlier will deal with the history of Bradford and the development of the Bradford trade, under the following sub-heads :- (I) Prehistoric archæology, for which $\mathrm{Mr}$. Butler Wood, chief librarian of the Bradford Free Libraries, is responsible : (2) the historical record of Bradford through mediaval times to the middle of the I 8 th century, which has been undertaken by Mr. Harry Speight; and (3) the social life and development of Bradford from the middle of the I8th century to the present, which is in the hands of Mr. Halliwell Sutcliffe, the novelist. To this section there will be addenda on the local dialect, the local folklore, and the local placenames, including street-names, which will be written by Mrs. Wm. Wright (of Oxford) and Mr. Butler Wood.

The second section of the volume, of which Mr. John Bacchus is sectional editor, will deal comprehensively with the Bradford industries and institutions. The following are sub-heads:--Introductory notice and description of the staples employed in the Bradford trade; description of the processes in combing, spinning, weaving, dyeing and finishing; merchanting in the textile trade ; the iron trade and machinery-making; the stone trade and minor industries; the Chamber of Commerce and the Exchange.

The third part of the book, which is under the sectional editorship of Mr. J. E. Wilson, will deal with the scientific material of the locality, the flora, fauna, geology, meteorology, climate and public health. There will be in addition a number of pages devoted to the topography of the district, for which Mr. J. H. Hastings is responsible.

In addition to the handbook, the Publications Committee have in preparation a series of small guides to the various places to which excursions are to be made. These will be issued in the form of a small portfolio, and each guide is being prepared on a scheme similar to that of the handbook, local specialists being called upon to describe the archrology, geology, botany and zoology of the various districts.

In regard to the accommodation of visitors, it is not anticipated that, in suite of the large influx of strangers, there will be any difficulty in finding comfortable quarters for everybody. Bradford is well provided with hotels, the two largest of which, the Midland and the Great Northern, can put up a great number of guests. All the available accommodation at the Royal Hotel has been secured by the local committee in order to provide for the secretaries of the different sections, who, of recent years, have been in the habit of lodging together. A large amount of private hospitality will be provided by the inhabitants of Bradford, and the Hospitality Committee is also drawing 